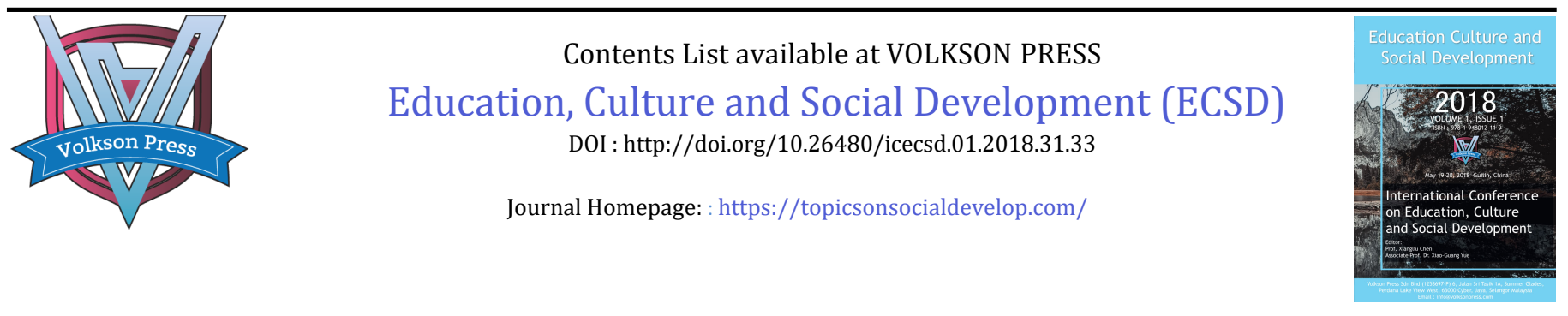

\title{
STUDY OF INVERTED SUBJECT IN FREE INVERSION AND ITS THAT-TRACE EFFECT
}

\author{
Zhang Wenguo ${ }^{1 *}$, Xiao Jingling ${ }^{2}$ \\ Department of Foreign languages Guilin University of Technology No.12, Jiangan Road, Guilin China. \\ *Corresponding Author Email: 185576928@qq.com
}

This is an open access article distributed under the Creative Commons Attribution License, which permits unrestricted use, distribution, and reproduction in any medium, provided the original work is properly cited

\section{ARTICLE DETAILS}

\section{Article History:}

Received 12 November 2017 Accepted 12 December 2017 Available online 1 January 2018

\section{ABSTRACT}

The inverted subject adjoins to VP. But his assumption is couched in a theoretical framework of a revised definition of ECP. That makes the analysis complicated and it betrays the principle of economy. The author of this paper proposed that the inverted Subject should right-adjoin to IP instead of VP. He applies many a testified principle and idea to verify his argument, including bounding nodes, barrier and the mechanism of $\gamma$-marking. Because in Italian the bounding nodes are CP and DP, IP is not a bounding nodes, as in English, so it is expected that adjunction to IP is language specific and the author tries to prove this assumption through the principles of barrier and the mechanism of $\gamma$-marking. The fact is that wh-phrase, in moving out of IP, adjoins to IP first, for adjunction to VP cannot account for the phenomenon that a wh-phrase extracting out of a wh-island, but no Subjection violation arises in Italian.

\section{KEYWORDS}

THAT-trace effect, adjunction, bounding node, barrier, mechanism of $\gamma$-marking.

\section{INTRODUCTION}

Consider (1) and (2):

1a. Who did you say would fix the car?

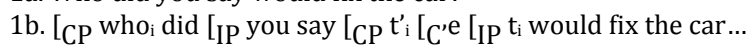

2a. *Who did you say that would fix the car?

2b. ${ }^{*}{ }_{\mathrm{CP}}$ whoi did [IP you say $\left[_{\mathrm{CP}} \mathrm{t}^{\prime}{ }_{\mathrm{i}}\left[_{\mathrm{C}}{ }^{\prime}\right.\right.$ that IIP $_{\text {IP }} \mathrm{t}_{\mathrm{i}}$ would fix the car...

(2) illustrate a phenomenon known as That-trace effect. We defined Thattrace effect as the phenomenon that the complementizer (that) cannot be followed by a trace (except in relative clauses) in some languages (e.g. English) [1-3]. Thus, in languages showing the that-t(race) effect, a subject cannot be extracted when it follows that. However, as noted, the that- $\mathrm{t}$ effect is not a universal phenomenon. For example, it is absent in Italian. "che" in Italian is a counterpart of "that in English. Notice we use "THATtrace" instead of "that-trace" to show that we here use the word "that" abstractly. The example below is [1]:
3a. Chi hai ditto
Who have-2S said che ha telefonato? that has phoned
3b. $\left[_{\mathrm{CP}}\right.$ chi hai ditto $\left[_{\mathrm{CP}} \mathrm{t}_{\text {chi }}{ }^{\prime}\left[_{\mathrm{C}^{\prime}}\right.\right.$ che $\left[_{\mathrm{IP}} \mathrm{t}_{\text {chi }}\right.$ ha telefonato ...

\section{ANALYSIS}

As shown in (3), it is possible to extract the subject of a clause introduced by the complementizer in Italian, in contrast to English.

In English, we say extraction out of this context gives rise to the THATtrace effect and ultimately to an ECP violation. But how can we account for it in Italian?

A researcher argues that the ECP violation seen in the Italian example (3) is only apparent [4]. Such sentences have a (roundabout) derivation that yields an LF-representation consistent with the ECP. The derivation in question is outlined in (4). It consists of two steps. The first step, shown in (4c), involves inversion of the subject to the VP-adjoined position following the verb. The second step, shown in (4d), involves whmovement of the inverted subject from the postverbal VP-adjoined position. FI in (4c) stands for Free inversion, and Wh-mov in (4d) for whmovement:

4a. Chi hai ditto che ha telefonato?

4b. DS: [IP pro hai ditto [CP che [IP chi I [VP ha telefonato ... 4c. FI: [IP pro hai ditto [ ${ }_{\mathrm{CP}}$ che [IP $_{\mathrm{IP}} \mathrm{pro}_{\mathrm{i}} \mathrm{I} \mathrm{VVP}_{\mathrm{VP}}$ [VP $_{\mathrm{VP}}$ ha telefonato] $\mathrm{chi}_{\mathrm{i}} \ldots$

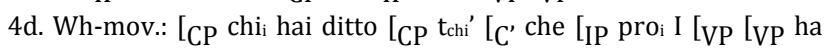
telefonato] $t_{\text {chi }} \ldots$

4e. SS: [CP chi hai ditto [CP tchi' ${ }_{C^{\prime}}$ che [IP proi I [VP [VP ha telefonato] $\mathrm{t}_{\mathrm{chi}} \ldots$

Rizzi's analysis is couched in a theoretical framework which assumes, first, that trace can satisfy the ECP via lexical government and not necessarily $\theta$-government, and secondly, that the VP-adjoined position is lexically governed by the verb. The consequence is that the trace in the VP-adjoined position shown in (4) satisfies the ECP [5].

But we see Rizzi makes the analysis really complicated, especially that his definition requires a revised version of ECP.

When we look at his analysis, we can't help doubting: Why must subject adjoin to the VP instead? Is there any reason? Since the subject is a full member of the IP, isn't it more reasonable if the subject adjoins to the IP? We had better start from discussing the bounding nodes in English.

In English, we know that the bounding nodes are IP and DP, while VP is not. For the wh-phrases in VP can always adjoin to the embedded VP containing it to circumvent its barrier hood when wh-phrase move out of VP, whereas it cannot adjoin to both IP and CP as the adjunction to VP as an escape hatch out of VP [6]. This is because if adjunction to these categories were possible, their barrier hood could be circumvented simply by adjoining to them. Instead, the wh-phrase moves to the embedded Spec, $\mathrm{CP}$ to avoid crossing IP and CP together. For instance:

5 a. Who did you say (that) John met?

5b. [CP who did [IP you [VP $t_{\text {who }}{ }^{\prime \prime \prime}\left[_{V P}\right.$ say $\left[_{C P} t_{w h o}{ }^{\prime \prime}\left[_{I P} J o h n\left[_{V P} t_{w h o}\right.\right.\right.$ ${ }_{\mathrm{VP}}$ meet $\mathrm{t}_{\text {who... }}$

But when the most embedded Spec,CP is already filled with another whphrase, then the barrierhood could be circumvented. For example:

6a. *How do you wonder whether John fixed the car?

6b. * [CP how do [IP you [VP thow' [VP wonder [CP whether [IP John [VP fix the car ...thow...

In Italian, however the bounding nodes are CP and DP, while IP does not count as a bounding node [1]. An example ad below: 
7a. tuo fratello, a cui mi domando Che storie abbiano raccontato your brother, to whom myself I-ask which stories they have told "? your brother, to whom I wonder which stories they told"

$7 \mathrm{~b}$.... CPP $_{\mathrm{C}}$ a cui [IP $_{\mathrm{IP}}$ mi domando ${ }_{\mathrm{CP}}$ che storie IIP $_{\text {abbiano raccontato }}$ $\mathrm{t}_{\text {che storie }} \ldots \mathrm{t}_{\mathrm{a} \text { cui }} \ldots$

The example (7) involves extraction out of a wh-island but does not exhibit a Subjacency violation. How can we account for it? We assume that in Italian that wh-phrase, in moving out of IP, adjoins to IP first, so that a more detailed derivation of (7) as in (8):

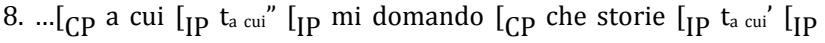
abbiano raccontato $t_{\text {che storie } \ldots} \mathrm{t}_{\mathrm{a}}$ cui $\ldots$

In (8), because the intermediate trace is not a full member of IP, both IP and $\mathrm{CP}$ are not barriers for it now (Because CP is L-marked, it is not an inherent barrier but a barrier by inheritance from IP. When IP is not a barrier any more, the CP won't be a barrier then) [7]. The consequence is that no barrier intervenes between the intermediate traces and the antecedent.

With this in mind, we now reanalyze the (4) above. The derivation is outlined below:

9a. Chi hai ditto che ha telefonato?

9b. DS: [IP pro hai ditto [ $\mathrm{CP}_{\mathrm{P}}$ che [IP chi I [VP ha telefonato ...

9c. FI: [IP pro hai ditto [CP che [IP [IP proi I [VP ha telefonato]] chi $\mathrm{i}_{\mathrm{i}} \ldots$

9d. Wh-mov.: [CP chi hai ditto [CP tchi $^{\prime}{ }_{\left[C^{\prime}\right.}$ che IIP $_{\text {IP }}$ proi I [VP ha telefonato]] $\mathrm{t}_{\mathrm{chi}} \ldots$

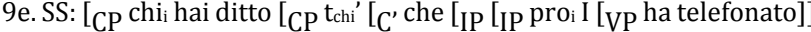
$\mathrm{t}_{\text {chi } \ldots}$

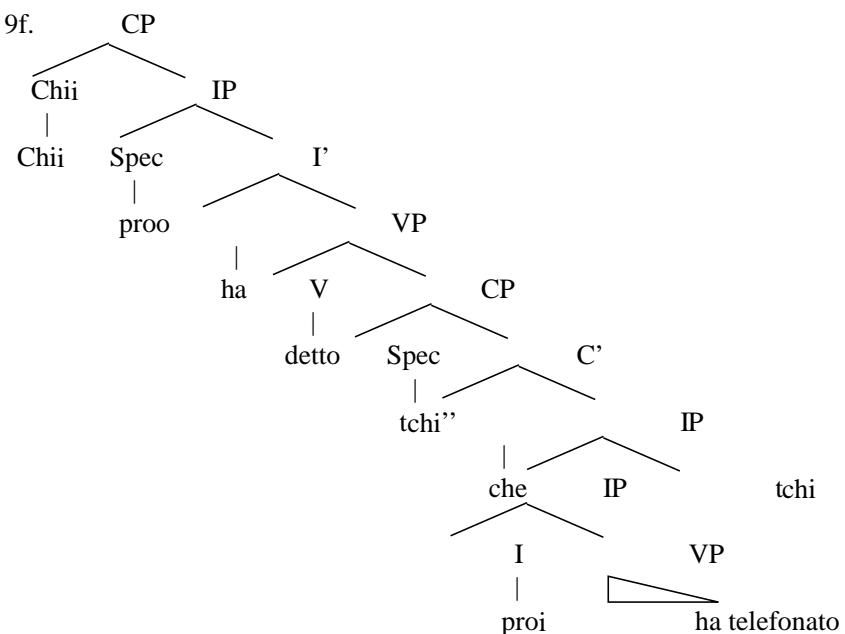

First, as in (9c), inversion of the subject wh-phrase adjoins to IP, of which it is a full member before the inversion and an associate member after the adjunction. Then, the move $\alpha$ applies to the inverted wh-subject from IPadjoined position [8]. Just as we discuss above, when adjoined to IP, IP is not a barrier of the inverted subject to movement. And ' $C^{\prime}$ is no longer a barrier. Recall the definition of barrier [3]:

i. $\gamma$ is a blocking category (BC) for $\beta$ iff $\gamma$ is not L-marked and $\gamma$ dominates $\beta$.

ii. $\gamma$ is a barrier for $\beta$ iff (a) or (b):

a. $\gamma$ immediately dominates $\delta, \delta$ a BC for $\beta$.

b. $\gamma$ is a BC for $\beta, \gamma \neq \mathrm{IP}$.

To make it simpler:

$\alpha$ is a barrier for $\beta$ iff:

i) $\alpha$ is not L-marked and $\alpha$ dominates $\beta$ ( $\alpha \neq$ IP) $\quad$ OR

ii) $\alpha$ immediately dominates $\gamma$, while $\gamma$ is non L-marked and $\gamma$ dominates $\beta$

$\mathrm{C}^{\prime}$ immediately dominate IP, so it is a barrier by inheritance to all the members that IP dominates. But the inverted subject is not a full member of IP but an associate member. That is to say it is not dominated by IP and $C^{\prime}$ is not a barrier to it $[9,10]$. This is the reason wh-movement can proceed directly from the inverted subject position to the Spec, CP of the embedded clause. and because there are no barrier intervenes between the antecedent and the intermediate trace, (9e) satisfied both ECP and Subjacency.

We can prove our assumption from another aspect. According to Rizzi the initial trace left by wh-movement must be an adjunct trace. It is a VP-joined position. Now we are trying to prove it is not that case.
Some researchers suggest an analysis which makes a crucial distinction between the levels at which argument traces and adjunct traces are licensed with respect to ECP [4]. The licensing mechanism takes the form of assigning the feature $[+/-\gamma]$ to the trace [11]. A trace is licensed with respect to ECP if it bears the (positive) feature specification $[+\gamma]$, and not to satisfy ECP if it bears the (negative) feature specification $[-\gamma]$. Argument traces such as subject and object traces must be licensed (i.e. must satisfy ECP) at SS. However, adjunct traces need not be licensed (i.e. need not satisfy ECP) until LF. The underlying idea is that all traces must satisfy ECP at $L F$ by virtue of bearing the feature specification $[+\gamma]$.

We now use this analysis to account for the inversion of the subject to the VP-adjoined position. (4e) is reproduced in (10):

10a. Chi hai ditto che ha telefonato?

10b. SS: $\gamma$-marking does not apply as a trace is an adjunct

[CP chi hai ditto [ ${ }_{\mathrm{CP}} \mathrm{t}_{\mathrm{chi}}{ }^{\prime}$ [C $_{\mathrm{C}}$ che [IP $_{\mathrm{P}} \mathrm{pro}_{\mathrm{i}} \mathrm{I}$ [VP $_{\mathrm{VPP}}$ ha telefonato] $t_{c h i} .$.

10c. LF: that-deletion applies followed by $\gamma$-marking $\rightarrow[+\gamma]$

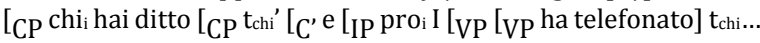
$[+\gamma]$

The trace involved is an adjunct-trace and therefore does not have to satisfy ECP until LF. Consequently, although the adjunction-trace is not properly governed at SS (10b), the mechanism of $\gamma$-marking does not apply to it at SS. Lasnik and Saito suggest that at the LF level the complementizer that deletes (affect $\alpha$ ) on the grounds that it is semantically empty and does not play a role in interpretation [12]. Once the complementizer is deleted, C' ceases to be a barrier to antecedentgovernment of the initial trace by the intermediate trace. Consequently the initial trace is assigned the feature $[+\gamma]$, thereby satisfying ECP.

With this in mind, let us assume that wh-phrase, in moving out of IP, adjoins to VP first. The derivation is outlined below:

11a. tuo fratello, a cui mi domando che storie abbiano raccontato

11b. SS: $\gamma$-marking does not apply as a trace is an adjunct

... [CP a cui [IP $\mathrm{t}_{\mathrm{a} \text { cui" }}$ [IP $_{\mathrm{C}}$ mi domando [CP che storie [IP pro I [VP $\mathrm{t}_{\mathrm{a}}$ cui' [VP abbiano raccontato $t_{\text {che storie }}$... $\mathrm{t}_{\mathrm{a}}$ cui..

11c. LF: that-deletion applies followed by $\gamma$-marking $\rightarrow[-\gamma]$

... [CP a cui [ [IP $\mathrm{t}_{\mathrm{a}}$ cui" [IP mi domando [CP che storie [IP pro I [VP $\mathrm{t}_{\mathrm{a}}$ cui' ${ }_{V P P}$ abbiano raccontato $t_{\text {che storie } \ldots} . \mathrm{t}_{\text {a cui }} \ldots$

Notice the feature specification the initial trace $t_{c h i}$ bears: $[-\gamma]$, that is to say, the (immediate) adjunction-trace is not properly governed at LF. Why? Because although the wh-phrase by adjoining to VP circumvents the barrierhood of IP, it is still cannot circumvent the barrier hood of CP, which becomes a barrier by inheritance from IP [13]. Usually this situation can be circumvented by moving through Spec,CP. However, this option is not available to the moved adjunct wh-phrase in (11) because the most embedded Spec,CP is already filled with another wh-phrase (che storie) [14-17].

However, if the wh-phrase adjoins to IP, the derivation is legitimate:

12a. SS: $\gamma$-marking does not apply as a trace is an adjunct

... [CP a cui [IP ta cuil $_{\text {IP }}$ mi domando [CP che storie [IP $t_{\text {a cui' }}$ [IP abbiano raccontato tche storie $\ldots . . t_{\text {a cui }} \ldots$

12b. LF: that-deletion applies followed by $\gamma$-marking $\rightarrow[+\gamma]$

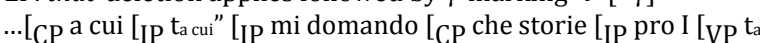
cui' $[$ VP abbiano raccontato tche storie $\ldots$. ta cui $\ldots$

So now we should assume that in Italian that wh-phrase, in moving out of IP, adjoins to IP instead of VP.

13a. Chi hai ditto che ha telefonato?

13b. SS: $\gamma$-marking does not apply as a trace is an adjunct

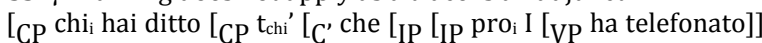
$\mathrm{t}_{\mathrm{chi} . .}$

13c. LF: that-deletion applies followed by $\gamma$-marking $\rightarrow[+\gamma]$

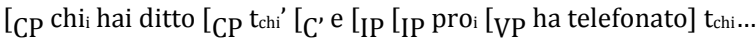
$[+\gamma]$

Tus the analysis outlined in (14) for Italian sentences with an inverted subject. The derivation in (14) is for both root and embedded clauses with an inverted subject:

14a. Ha telefonato Gianni.

has phoned Gianni

14b. DS: [IP Gianni I [VP ha telephonato ...

14b. SS: [IP [IP pro $_{\mathrm{i}} \mathrm{I}$ [VP ha telephonato] (Gianni) $)_{\mathrm{i}} .$. 


\section{CONCLUSION}

At DS the subject is situated in Spec,IP, the canonical subject position, as shown in (14b). Move $\alpha$ then applies to the subject and right-adjoins to IP, as shown in (14c). The landing site of the moved subject (the IP-adjoined position) c-commands the initial (DS) position of the subject. Thus, the empty category left in the subject position is antecedent-governed, and therefore it satisfies ECP. The only difference between English and Italian is that in Italian a subject can moves to the right while in English it can only moves to the left. This is because the overt/rich Agr category license the null subject.

\section{ACKNOWLEDGMENTS}

This study is subsidized by Guangxi Education Department Youth Teacher Project No. KY2016LX118, No.KY2016LX104 and No.2017KY0224.

\section{ABOUT THE AUTHOR}

Zhang Wenguo ${ }^{1}$, MA, assistant professor in Guilin University of Technology, focusing on formal syntax and theoretical linguistics.

Xiao Jingling2, MA, assistant professor in Guilin University of Technology, focusing on college English teaching and corpus linguistic studies.

\section{REFERENCES}

[1] Noam, C. 1981. Lectures on Government and Binding. Dordrecht: Foris Publications.

[2] Noam, C. 1986a. Knowledge of Language: Its Nature, Origin and Use. New York: Praeger.

[3] Noam, C. 1986b. Barrier. The MIT Press, Cambridge, MA.

[4] Guglielmo, C. 1990. Types of A'-dependencies. Cambridge, Mass.: MIT Press.

[5] David, C. 1997. A Dictionary of Linguistics and Phonetics. Blackwell Publishers Ltd.

[6] James, H.C.T. 1982. Logical Relations in Chinese and the Theory of Grammar. Ph.D. dissertation, MIT; revised edition published by Garland Publishers, New York.

[7] James, H.C.T. 1988. Wo pao de kuai and Chinese phrase structure. Language, 64, 274-311.

[8] James, H.C.T. 1992. Complex predicates in control. In Richard Larson, Utpal Lahiri, Sabine Iatridou, and James Higginbotham (eds.), Control and Grammar, 109-147. Dordrecht: Kluwer Academic Publishers.

[9] James, H.C.T. 1994. "Verb Movement and Some Syntax-Semantics Mismatches in Chinese," Chinese Languages and Linguistics 2, 587-613.

[10] James, H.C.T. 1997. On lexical structure and syntactic projection. Chinese Languages and Linguistics 3, 45-89.

[11] James, H.C.T. 2005. Syntactic analyticity and the other end of the parameter, lecture notes, Harvard University.

[12] Lasnik, H., Saito, M. 1984. On the nature of proper Government. Linguistic Inquiry, 14, 235-89.

[13] Jamal, 0. 1999. Introducing transformational Grammar: From Principles and Parameters to Minimalism. Edward Arnold.

[14] Andrew, R. 1988. Transformational Grammar. Cambridge University Press.

[15] Andrew, R. 2004. Minimalist Syntax. Cambridge University Press.

[16] Rizzi, L. 1982. Issues in Italian Syntax. Dordrecht: Foris.

[17] Rizzi, L. 1990. Relativized minimality. Cambridge, Mass.: MIT Press.

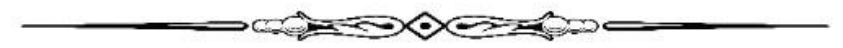

